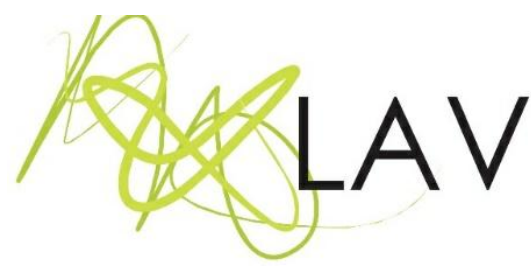

\title{
Das infâncias estriadas às infâncias lisas: experimentar trajetos de arte na educação
} From the striated childhoods to the smooth childhoods: experiencing art paths on
education

\author{
Alexandre Filordi de Carvalhoi \\ Universidade Federal de Lavras e Universidade Federal de São Paulo
}

\begin{abstract}
Resumo
Este artigo investiga a teoria dos trajetos estriados e lisos, proposta inicialmente por Deleuze e Guattari, e ampliada por Guattari. Sustenta-se que existem dois tipos de experiências com a infância: a estriada e a lisa. A hipótese é que a infância estriada se deriva da política de trajeto de modelização subjetiva cuja síntese de dominação situa-se no Estado. Em oposição, situa-se a infância lisa, suscitando experiências singulares a partir de trajetos de uma política de turbilhão e experimentação. Em ambos os casos, há uma formação subjetiva em questão cuja recepção da arte é necessária para uma formação subjetiva da infância estriada ou lisa. Para tanto, empreendeu-se uma pesquisa de revisão da literatura atinente ao escopo teórico. Ao cabo, defende-se que é urgente deflagrar uma política de alisamento da infância para se interpor, no âmbito da educação e da arte, à modelagem subjetiva de dominação.
\end{abstract}

Palavras-chave: infância, arte, educação, subjetividade.

\begin{abstract}
This paper investigates the theory of striated and smooth paths initially proposed by Deleuze and Guattari, but it expands based on Guattari's thought. It is argued that there are two types of experiences with childhood: striated and smooth. The hypothesis is that striated childhood comes from the subjective modeling path policy whose synthesis of domination is located in the State. By contrast, there is a smooth childhood, giving rise to the singular experiences based on paths of a vortical spiral and experimentation policy. In both cases, there is a subjective formation in question whose reception of art is necessary for a subjective formation of striated or smooth childhood. For this purpose, a literature review regarding its theoretical scope has been undertaken. As a result, it is argued that there is an urgent need to outbreak a childhood smoothing policy in order to interpose, in the field of Education and Art, to the subjective modeling of domination.
\end{abstract}

Keywords: childhood, art, Education, subjectivity. 


\section{Traços gerais do artigo}

O inimaginável é imaginável. (SZYMBORSKA, 2016, p. 185)

Quando Freinet (2016, p. 63, grifo original) considerou que se "quiséssemos estar inteiramente ao serviço da criança, deveríamos destronar os manuais", ele não estava apenas abrangendo a centralidade do livro, da apostila ou de tudo que representasse o conteudismo na educação. Numa compreensão expansiva, Freinet situava a relação de servidão que a criança constantemente se encontra com relação ao adulto que prepara a sua formação. Afinal de contas, são os adultos que escrevem 'os manuais' para a criança e delineiam a relação currículo com o que se deve aprender. Assim, no lugar de a criança se tornar o centro ativo da educação, corre-se o risco de ela se reduzir a um terminal passivo de modelização. É tudo isso que está em questão no 'destronar os manuais'.

Além disso, tais termos poderiam ser atualizados pela seguinte indagação: o que faz a vez dos manuais na educação contemporânea? Talvez não precisemos mais dos manuais, pois, se levarmos a bom termo a perspectiva que Guattari (1989; 1992; 2011a; $2011 b$; 2012) delineou, a sociedade se transformou num grande manual formativo em função da homogeneização de componentes simbólicos, extensivos à escala industrial e global (CARR, 2013; CARVALHO, 2019; MONTES, 2002; STEINBERG; KINCHELOE, 2001), voltados implacavelmente para a formação modelar de modos de ser.

A questão central que este artigo investiga é justamente o fato de a infância ser objeto primeiro das estratégias de modelização subjetivas e quais as consequências decorrentes disso. A infância se reduziu a um trono idealizado para tipificar a potência de toda expressividade das crianças. Como será mostrado, há uma política de trajetos para a infância que pré determinam os circuitos pelos quais seus componentes emocionais, psíquicos, cognitivos, afetivos e corpóreos devem se adaptar. É algo peculiar da contemporaneidade e instituída por políticas públicas de educação (BRASIL, 2018; CARVALHO, 2020).

Para compreender tal dimensão, o artigo explora a teoria dos trajetos estriados e lisos proposta por Deleuze e Guattari (2012). Entretanto, para aprofundá-la, privilegia-se o pensamento de Guattari (1985; 1989; 1992; 2009; 2011a; 2011b; 2012; 2013; 2016). Inicia-se pela questão do 'estriado' para, ao mesmo tempo, calibrar tal campo teórico face ao que será denominado de infância estriada, perscrutando a implicação analítica que ela aporta para o campo da educação, contudo, pela ênfase da formação estética atravessada pela arte.

Revista Digital do LAV - Santa Maria - vol. 14, n. 2, p. 07 - 29 - mai./ago. 2021 ISSN 1983 - 7348 
Nessa etapa, o que será denominado de arte do Estado sintetiza a convergência das políticas de trajetos estriados para a infância, sem desconsiderar-se que os componentes simbólicos são capturados por uma constante pedagogização estriada, justamente para fazer sentido às demandas de modelização adaptativa da infância ao sistema que não prescinde de "uma multiplicidade de pequenos espaços de adaptação pontual" (GUATTARI, 2012, p. 43). A arte, nesse sentido, tem um papel irrecusável: limitar a experimentação sensitiva, perceptiva, estética e dar direção aos fluxos criativos para que se reduzam aos encaixes sociais substancializados pelos trajetos do Estado.

Mas à medida que as análises avançam para a concepção de que a infância pode compor-se em e com outras direções, ou melhor, em experiência 'passante', fora dos circuitos das estrias do Estado, nos termos de Deligny (2018b), diferente política de trajeto é suscitada para dar conta dos enfrentamentos da infância fechada em circuitos programados e controlados. À essa altura, explorar-se-ão a concepção de infância lisa e como a arte compõe trajeto demandado na produção do que será denominado de trajetos de turbilhão de passagens para a infância.

Na proporção inversa, analisar a correlação da infância lisa com a arte implica a experimentação (BLANCHOT, 2007) de matérias de expressão que compõem com a criança a afirmação de uma infância não mais demandada pelas políticas de trajetos modelares do Estado. A questão é explorar conteúdo e expressão que se habilitam como "suporte" de uma produção de afetos e de perceptos que tenderá cada vez mais a se excentrar em relação aos quadros e coordenadas pré-formatadas" (GUATTARI, 1992, p. 129).

Vale mencionar que, ao longo do artigo, preferiu-se sublinhar infância, no singular, para manter a ênfase em uma singularização processual, isto é, de política de trajeto singular, capaz de produzir coeficiente diferencial em todas as infâncias. Fora isso, a literatura especializada (CHOMBART DE LAUWE, 1991; SCHÉRER, 2009; SKLIAR, 2016; WINNICOTT, 2019), há muito tempo, remarcou que "não há uma infância. Existem muitas infâncias, pois as infâncias são heterotopias", nos termos de Carvalho (2016, p. 78). Não se despreza tal feito, apenas se opta por um tom necessário ao que se pretende enfatizar: contra a modelização geral da infância estriada, o lugar da infância lisa e sempre singularizada.

Também é importante mencionar que a arte é considerada no artigo a partir da ampla chave analítica da criação semiótica, no sentido que toda criação é sempre dissidente (GUATTARI; ROLNIK, 2005). Não à toa, persegue-se a distinção entre arte modelar, ou de estriamento do Estado, e arte diagramática, atinente à política de trajetos lisos e experimentais. Arte, no limite, abrange toda criatividade subjetiva (GUATTARI, 
1992) que, nesse caso, desprograma a infância fadada aos mesmos componentes semióticos de expressão, sensação, valoração e perspectivismo da vida.

Para tanto, o artigo procede uma vasta revisão bibliográfica que visa a circular as hipóteses iniciais lançadas por Deleuze e Guattari (2012) acerca do estriado e do liso. Entretanto, como a concepção original dos pensadores não privilegiou a educação, tampouco a arte, procede-se com uma análise bibliográfica transversal para se alcançar os objetivos acima propostos.

Do ponto de vista formal, o artigo se desenvolve em duas partes. Na primeira, denominada Infâncias estriadas: a arte como trajeto de modelagem subjetiva de dominação, investiga-se a relação tríplice entre o que são as infâncias estriadas e as correlações com a demanda de uma arte de trajeto modelar coextensiva às funcionalidades de uma subjetividade de dominação, isto é, de Estado. Na etapa subsequente, as Infâncias lisas: a arte como trajeto de turbilhão de passagens, abrange-se a compreensão do que são as infâncias lisas e sua correlação com a arte em função da noção de turbilhão (DELEUZE, GUATTARI, 2012). Esta, por sua vez, aporta a problematização para outras políticas de trajetos da infância, com relações peculiares quando se pensa na relação infância e arte.

\title{
Infâncias estriadas: a arte como trajeto de modelagem subjetiva de dominação
}

\author{
A história do Estado Único não conhece nenhum \\ caso em que alguma voz tenha ousado se \\ erguer contra o majestoso uníssono (ZAMIÁTIN, \\ 2017, p. 156).
}

Nada além de réplicas, réplicas a perder de vista (BURROUGHS, 2016, p. 185).

Estriar a infância diz respeito a uma política de se produzir trajetos para as crianças, a partir do controle de seus sentimentos e de suas experiências intensas (WINNICOTT, 2019); da supressão e do manejo de seus tempos presentes (STERN, 2007), sob o eterno ritual da disciplina do mundo dos adultos e da racionalização empenhada em justificar seus ciclos de temporalidades; das idealizações afetivas, perceptivas, comportamentais e atitudinais (CHOMBART DE LAUWE, 1991), já cristalizadas como projeção demandada ao adulto devindo na criança; das estratégias econômico-corporativas para se homogeneizar e se deter o controle comercial, pela lógica do mercado, das potências físicas, emocionais, afetivas, cognitivas e criativas das crianças (STEINBERG; KINCHELOE, 2001), somadas a todo processo de modelagem subjetiva (GUATTARI, 1985, 1992, 2011a, 2011b). 
"O espaço homogêneo não é em absoluto um espaço liso, ao contrário, é a forma do espaço estriado", assinalaram Deleuze e Guattari (2012, p. 39). Cada criança é inscrita em um socius estriado, pois os espaços de seus territórios existenciais são dispostos a partir de uma série de circuitos de trânsito institucional. Circuitos hospital-família, famíliaescola, escola-vizinhança, sociedade-mercado, camaradagem-jogos-brincadeirasprescritas e sensibilidade-ludo-comercial-programada funcionam como verdadeiros pedágios nas passagens dos trajetos que possibilitam apenas certos fazeres, estares e modos de ser.

É próprio do estriado ser limitado e limitante. Em primeiro lugar, porque o estriado concerne à própria micropolítica que institucionaliza o cotidiano da criança, quase que em sua totalidade. Entre o que se autoriza ela a fazer ou não, a ir ou não, a pegar ou não, a experimentar ou não, o que se delineia são opções excludentes: ou isto ou aquilo. $O$ estriado, assim, está para uma política de trajetos absolutamente controlados. Entretanto, em segundo lugar, tais ocorrências são planos de aderência ao espaço homogêneo maior, cuja representação global é o Estado. Se "uma das tarefas fundamentais do Estado é estriar o espaço sobre o qual reina" (DELEUZE; GUATTARI, 2012, p. 63), toda instituição, estrutura social, codificação legal ou epistemológica, além de planos subjetivos autorizados, convergirão para os fluxos do poder do estriamento a reconhecer somente o que se é proposto pelo Estado.

Há uma infância do Estado e de Estado, assim como há as políticas educacionais de Estado; a prefiguração da família reconhecida por ele; o currículo institucionalizado, gerando passagens controladas e fluxos de conhecimento presos na diplomacia das etapas, das sucessões, dos ciclos, dos controles, das provas, das exigências e dos rituais. A escola, aqui, é o reino da linguagem oficial do Estado (MONTES, 2002). Nela, as crianças são introduzidas, antes de mais nada, para se tornarem fluentes nas linguagens de sobrecodificação existencial. Sobrecodificar envolve demandas de circuitos de produção subjetiva cujos resultados - outputs - são derivados de regras constantes de retroalimentação - inputs - do que apenas o Estado prescreve e defende oficialmente ${ }^{1}$.

Aqui se situam amplas estratégias de estriamento da infância, ou seja, séries de componentes de passagens que precisam funcionar como modelagem de subjetividade

\footnotetext{
${ }^{1}$ É importante ter em mente que nada disso concerne à defesa da destruição do Estado ou de seu sucateamento empenhados pelo neoliberalismo contemporâneo. É preciso manter o fio da argumentação dentro do contexto que Deleuze e Guattari estão propondo como crítica ao Estado. De modo preciso e ao que interessa na argumentação, o Estado é o nome que se dá a uma conjunção sintética de onde emana e para onde se convergem os estriamentos. Para uma análise acerca da defesa do Estado de direito à educação universal, pública e com qualidade, consultar Carvalho (2020).
}

Revista Digital do LAV - Santa Maria - vol. 14, n. 2, p. 07 - 29 - mai./ago. 2021 ISSN 1983 - 7348 http://dx.doi.org/10.5902/1983734865645 
dominante. É nessa direção que se poderia compreender a fórmula de Schérer (2009, p. 35):

É preciso libertar a criança da 'infância', quero dizer, dessa situação de controle estrito e, a pretexto de amadurecimento, dessa interiorização das coações e dos comportamentos embrutecedores, em relação aos adultos, que lhe são incutidos pela pedagogia.

É próprio mesmo das estrias os controles, por isso a necessidade de se interiorizar obrigações, coações e antecipações modelares, e a necessidade confluente de teorias e práticas educativas apoiadas pelo Estado, a 'pedagogia', reconhecida tão somente como campo pelo qual as experiências educativas prevalecem conforme a Base Nacional Comum Curricular (BRASIL, 2018), doravante BNCC, ou seja, adequadas ao mapeamento dos circuitos possíveis e entabulados para 'todas' as etapas, bem como para 'todos' os campos de experiência das crianças. Aqui, uma infância já foi estriada para as crianças.

Ao mesmo tempo em que sintetiza tal horizonte, a concepção que Guattari (2012, p. 468) aporta para o Estado amplia o escopo de seu projeto de homogeneização espacial, isto é, de a tudo englobar: "Estado é um lugar de conversibilidade geral de todos os sistemas de valores econômicos, simbólicos, significantes e de desejo". Como se vê, nada escapa à volúpia sedentária do Estado ${ }^{2}$ cujos planos para o trânsito da infância precisam ser projetados, controlados e aplicados, inclusive, mas sobretudo, os planos simbólicos, em que a prefiguração de artes estatizantes, responsáveis por estriar a criança para comprimi-la com determinada infância, compartimentaliza-se ali.

Se houve um tempo que a arte canalizava os fluxos de poder da aristocracia, da igreja, depois do Estado - inclusive os fascistas - (HUIZINGA, 2016), sempre atenta à sua utilidade para alguma forma de vida, era justamente pelo fato de a arte não se livrar dos coeficientes de estriagem a incidir sobre ela. Sempre houve e haverá uma arte estriada, funcionando como "sobrecodificação das máquinas significantes estáticas" (GUATTARI, 2011b, p. 39). Uma máquina significante diz respeito às abrangentes formas pelas quais a produção artística sofre incidência de relações de poder, a fim de se reduzir ao empenho de uma representação ensejada. Desse modo, a arte flerta com um poder constituinte, reiterando trajetos perceptivos, sensitivos e estéticos que não ousam ir além da elegância

\footnotetext{
2 Embora a relação da política do estriado e do liso seja coextensiva às análises que Deleuze e Guattari (2012) empreenderam acerca do nomadismo, com suas máquinas de guerra, e do sedentarismo; e Guattari (1989; 2011a; 2011b) acerca das coordenadas modelares e dos diagramatismos, por evidente impossibilidade de a tudo abranger, o artigo privilegia apenas a relação política de estriamento com a modelagem e a política de lisagem com o diagramatismo guattariano. Para uma abordagem mais ampla do estriado e do liso com nomadismomáquina de guerra e sedentarismo-Estado consultar Carvalho e Gallo (2010).
} 
instituída daquilo que se negocia como função da arte instaurada. Por conseguinte, a arte se estria por demanda funcional e aplicada ao Estado.

A expressão de Montes (2002) poderia ser aqui evocada: a arte pode ser um 'curral da infância'. Encerrar as crianças na programação controlada de acesso e de experimento de conteúdos e expressões artísticos reduzidos só faz sentido à política de estriamento da infância. O mundo infantil, assim, condensa-se e se reduz aos circuitos simbólicos e imaginários apenas sancionados por limites definidos de antemão por uma arte do Estado. Aos poucos, vão se estruturando trajetos reincidentes cuja finalidade é a modelização de uma subjetividade decretada pelos valores capazes de tipificar oficialmente a potencialidade artística da criança. Desde então, o corpo nem pode se sujar de tinta; as unhas não podem se atolar no barro, na argila, nas massas; as vozes não podem sair do controle; a circulação coletiva das crianças têm de ser encasteladas na miniaturização das grandes vigilâncias; os meninos não podem se fantasiar de princesas ou serem bruxas malvadas; as meninas não reinarão como Arthur e seus cavaleiros.

A força simbólica da arte, desde muito cedo, precisa passar por comportas reguladoras de fluxos. Para tanto, a arte estria o corpo para adequá-lo ao plano homogêneo de conteúdos que veiculam consensos majoritários perceptivos. Nenhuma submissão social ocorre sem uma política de submissão simbólica. Logo, a arte, na educação infantil, ao ser estriada, une-se, tal como a luva com a mão, com a infância estriada. Uma é feita para a outra, porque o que está em questão é a traduzibilidade de ressonâncias de significações, mediadas para se alcançar e operar de modo massivo, universal e estrutural o que a infância deve ser.

Estriadas pelo Estado, infância e arte funcionam como viés de confirmação. No plano da educação, a arte passa a fomentar arquétipos de generalidades, distanciamentos das pulsões descontroladas da vida, filtragem de experimentação imaginária, simbólica, tátil, ludoexpressiva, pictórica, imagética, sonora, melódica e corpórea, visando a reforçar 'esquemas de pilotagem' subjetivos, conforme propõe Guattari (2013, p. 374), responsáveis por "modelizar a percepção, o imaginário e os valores de referência" de cada uma das crianças.

A essa altura, o curral da infância se fundamenta por uma utopia pedagógica para a infância. Schérer (2009) entende por utopia pedagógica o fascínio projetivo de uma condição educacional que deflagra, como se fossem camisas de força, o monopólio educativo do qual o Estado não abre mão. Toda arte estriada na utopia pedagógica está prefigurada no monopólio educativo. As demandas por se promover certos e tão 
determinados 'campos de experiências' com arte estão postos na BNCC (BRASIL, 2018, p. 44, grifos originais):

$\mathrm{Na}$ Educação Infantil, as aprendizagens essenciais compreendem tanto comportamentos, habilidades e conhecimentos quanto vivências que promovem aprendizagem e desenvolvimento nos diversos campos de experiências, sempre tomando as interações e a brincadeira como eixos estruturantes. Essas aprendizagens, portanto, constituem-se como objetivos de aprendizagem e desenvolvimento.

Em tal concepção oficial, o mais estriado não está no fato de se reduzir toda possibilidade da criança ao infantil por intermédio do sinônimo de aprendizagem essencial, tampouco se encontra a radicalidade da estriagem na já cansada epistemologia normativa do desenvolvimento infantil ou nos feixes estruturalizantes a funcionar como poderes do Estado educativo. O ponto mais vertiginoso encontra-se na convergência do uso da arte para promover competências e habilidades cujo destaque é a função adaptativa a uma sociedade que execra a não utilidade da simbólica artística. A arte contra a política de estriamento é inconcebível no curral da infância e nos fundamentos utópicos da pedagogia estatizante. A arte, aqui, tem o seu encontro irrevogável com

A utopia [que] é a quimera de reprimir, transformar e controlar o indivíduo em cada etapa de seu desenvolvimento: projeto ilusório sempre adiado para o futuro - de instauração de uma ordem social, enfim, definitiva e dotada de todos os recursos de segurança, em que os integrantes do corpo social, formados do mesmo modo, convergem por vontade própria para o mesmo objetivo (SCHÉRER, 2009, p. 26, acréscimo nosso).

Quando Chombart de Lauwe (1991, p. 54) ressalta o caráter de idealização que a concepção de infância traz consigo para as crianças, não deixa de ignorar o quanto o manejo das representações humanas no plano das artes, quaisquer que sejam, e com sua simbolização, ocorre com o intuito de fazer se "expressar os mesmos valores fixados sobre a criança idealizada". Uma imagem pode ser fornecida para a criança idealizada. Pode-se dizer que a criança idealizada é aquela que se faz encaixar em um template da infância. 0 que não encaixa é dispensado, normalizado, tratado, medicalizado, pedagogizado, em suma, estriado.

Ora, todo trânsito e toda experiência com múltiplas possibilidades com as artes desempenham papel relevante aí, pois as artes manejam amplas frentes da plasticidade infantil da criança. Diferentemente de disciplinas precipuamente cerebrais, a arte, para além de coeficientes cognitivos, convoca a pluridimensionalidade da condição humana. Todos os sentidos, toda a plástica corporal, toda a economia simbólica consciente e inconsciente, os fluxos da imaginação, as fronteiras entre o real e o imaginário; tudo isso 
encontra-se nas artes. Estriar a arte é fundamental para se forjar respostas esquemáticas e condicionadas ao que o Estado pretende autorizar para melhor controlar os trajetos artísticos a funcionar como cifra de antemão decifrada. Se não for assim, a arte pode se tornar um potente descarrilamento nos trilhos formativos.

Mas não podemos nos enganar, pois o amplo espectro da estriagem do Estado privatiza a arte do modo mais insidioso possível, a partir do instante em que o template da infância se dispõe para as crianças com o mínimo possível de resíduo de escape:

Desde a mais tenra idade, o espírito, a sensibilidade, os comportamentos e as fantasias das crianças são confeccionadas de modo a torná-las compatíveis com os processos da vida social e produtiva. Não apenas isso, eu insisto, no nível das representações e dos afetos: um bebê de seis meses colocado diante da tela estrutura sua percepção fixando seus olhos na tela da televisão. A concentração de sua atenção sobre certo tipo de objeto também faz parte da produção de sua subjetividade (GUATTARI, 2009, p. 129).

Estruturar a percepção; modelar a sensibilidade; ordenar e hierarquizar valores simbólicos, excluindo tantos outros; gerar uma gramática de poder estético, por intermédio da qual escolhas padronizadas orquestram os campos de experiências das crianças, não deixam de ser a aposta cotidiano da arte como trajeto de modelagem subjetiva de sujeição. A arte, desse ponto de vista, é uma réplica do Estado, assim como a família; a sociedade de consumo; os quites de iniciação à arte, produzidos pelas grandes corporações da indústria infantil, programando as crianças para dissolver suas infâncias nos mesmos lagos dos artefatos de consumo. Faz sentido, portanto, os termos de Deleuze e Guattari (2012, p. 64): "a réplica do Estado consiste em estriar o espaço, contra tudo o que ameaça a transbordá-Io".

De qualquer perspectiva da educação infantil, a arte que não transborda o Estado auxilia-o no fortalecimento de toda política de estriagem. A infância não passa, assim, de uma usinagem de semiótica funcional. A sua experiência com as artes deixa de ser experimentação e se reduz à formação artística protocolar. Se Blanchot (2007, p. 191) mencionava que o sinal peculiar da experimentação "é o infinito questionar", salta aos olhos que a impossibilidade de se sair do curral da infância com seus templates simbólicos, na verdade, é sinal da arte estriada, o modelar para o infinito aceitar. A lógica há de se fechar assim:

É desde a infância que se instaura a máquina de produção de subjetividade capitalística, desde a entrada da criança no mundo das línguas dominantes, com todos os modelos tanto imaginários 
quanto técnicos nos quais ela deve se inserir (GUATTARI; ROLNIK, 2005, p. 49).

A criança poderia encontrar-se com a infância, concebida como trajetos "onde tudo é indeciso" e onde tudo é um "viver num desvio perpétuo", nos termos de Blanchot (2007, p. 28); no lugar disso, a criança se vê estriada constantemente para que sua vitalidade se institucionalize. A arte é uma das tantas dobradiças do estriamento do Estado. Sua localização no ambiente escolar não nos deixa enganar: "a máquina de ensino obrigatório não tem por objetivo principal transmitir informações, conhecimentos, 'uma' cultura; mas transformar, do início ao fim, as coordenadas semióticas da infância" (GUATTARI, 2011b, p. 190). A arte encontra-se nas coordenadas semióticas, isto é, na indissociável relação de todo circuito de conteúdo e de expressão atuando na política de sensibilização e percepção dos sujeitos. A arte, desse modo, não é indiferente a cada possibilidade de conteúdo e de expressão, quando estes assinalam os roteiros de tipificação de trajetos estriados que demandam subjetividades aderentes às formas e às simbólicas exigidas. A Arte estriada reduz-se, assim, a uma grande ordem icônica, mero marcador funcional de como as crianças devem ser introduzidas a um sistema de modelagem subjetiva constante e programada. Numa ponta persiste o seguinte diagnóstico:

Tudo concorre, na maquinaria da Escola, ao assujeitamento generalizado. [...] O sistema de emprego do tempo, os ritmos de trabalho, as constrições impostas ao exercício da palavra, os entraves nos movimentos do espaço, e mesmo, muito frequentemente, a interdição pura e simples de toda expressão de componentes semióticos corporais, musicais, plásticos etc. (GUATTARI, 1989, p. 69).

E na outra ponta, se voltássemos ao ideário de estriamento da infância pelo Estado, notaríamos o inquestionável da arte programada como circuito de modelização subjetiva. É que tudo está onde se deve começar: pela criança a ser conformada. Conforme a OCDE (2018),

Cada vez mais os empregadores procuram atrair alunos que se adaptam facilmente e são capazes de aplicar e transferir suas habilidades e conhecimentos para novos contextos. A prontidão para o trabalho em um mundo interconectado exige que os jovens compreendam a dinâmica complexa da globalização (OCDE, 2018, p. 5, grifos nossos).

Mas o que se suscitaria se a arte fosse abrangente experiência de desadaptação à política de modelagem subjetiva de dominação? E que outras políticas de trajetos eclodiriam, inclusive com implicações para as infâncias fora dos currais e dos templates, fora das ordens icônicas do Estado? 


\section{Infâncias lisas: a arte como trajeto de turbilhão de passagens}

$A$ arte nos deixa inquietos, insatisfeitos. E o nosso sistema industrial não pode se dar ao luxo de deixar que isso aconteça (MILLER, 2004, p. 158).

O cúmulo do estriamento na infância, sob incansáveis manejos políticos dos trajetos interpostos pela miríade de miniaturização do Estado, transforma a criança num potentado da infância confiscada. Em outros termos, o estriamento homogeneíza abordagens teóricas e empíricas a retroalimentar marcadores sociais que programam os circuitos da infância. A arte do Estado não passa de uma das ferramentas validadas para deixar tudo em ordem para a criança alcançar uma infância normal, ou seja, contemplada previamente nos circuitos pelos quais devem passar suas energias, percepções, criatividades e corporeidades, mas também seus afetos e componentes expressivos.

Fora, contudo, do estriamento, a criança emana outros sinais de infância, ou seja, condições outras de se fazer em trajeto. Nas e com as infâncias lisas, há outras políticas de trajetos que emergem e outras consistências de territórios existenciais promanam. Longe das políticas de modelização, resistentes aos espaços homogêneos, próprios ao estriamento, produtoras de singularidades icônicas a partir da própria diferença de cada criança, a infância lisa gera o turbilhonar.

Deleuze e Guattari (2012) chegam a mencionar que a condição da política de alisamento é o "modelo turbilhonar". Não podemos entender esse modelo como decalque igualitário a conduzir aos mesmos sensos e consensos, espécie de condição universal de reduplicação de juízos, técnicas e procedimentos. O modelo é o nome que se dá às estratégias que se inventam a partir do próprio turbilhonar, logo, ele não está dado de antemão. Com efeito,

O modelo é turbilhonar, num espaço aberto onde as coisas-fluxo se distribuem, em vez de distribuir um espaço fechado para coisas lineares e sólidas. É a diferença entre um espaço liso (vetorial, projetivo ou topológico) e um espaço estriado (métrico). (DELEUZE; GUATTARI, 1992, p. 26, grifos originais).

Os termos revelam as condições: a infância lisa é turbilhonar à medida que recusa o seu fechamento pelas prefigurações, de toda ordem advindas do Estado, isto é, dos oficialismos estriadores. Concebida apenas como passagem, a infância lisa experimenta vetores abertos. Portanto, ela está sempre no meio, desconhecendo finalidades preestabelecidas e saídas programadas. A infância lisa é semelhante ao projétil que atravessa as cargas identitárias, funcionando como jugo condicionante de fases, etapas e desenvolvimentos. De topos em topos, a infância lisa não se localiza em qualquer métrica. 
Esses fetiches do estriamento, da quantificação dos testes de Q.I. à performance do PISA, passando pela quantificação medicamentosa e a nota escolar, são abominações às infâncias lisas.

É próprio do turbilhão embaralhar a lógica estriada, rompê-la, sabotá-la, atravessála e jamais reproduzi-la. O turbilhão é o que abre passagem ao liso, daí a razão de se falar em 'modelo turbilhonar', pois o liso precisa escorrer, seguir, passar, alcançar outras experiências, encontrando espaço topológico. Há de se considerar que "seguir não é o mesmo que reproduzir, e nunca se segue a fim de reproduzir" (DELEUZE; GUATTARI, 2012, p. 41, grifos originais). A infância lisa é sempre variável. Ela não se compõe com as passagens marcadas pelo Estado e toda sua máquina de burocracia imperial, que a tudo abrange. A infância lisa é que permite a infância, experimentando-a na proporção que a engendra. Contra-hegemônica e antiestatal, porém, aberta e experimental, tal infância nos arranca da lógica do estriamento e concebe outra política de trajetos para si, no entanto, fora dos limites e das limitações. Em suma, "[a] variabilidade, a plurivocidade das direções é um traço essencial dos espaços lisos, do tipo rizoma, e que modifica sua cartografia" (DELEUZE; GUATTARI, 2012, p. 57).

Duas problematizações evidenciam-se como marcadores de longo alcance. De um lado, vemos porque é preciso controlar a infância por infindáveis estratégias de estriamento. Deixá-la solta é permitir o confuso turbilhonar agir. E isso embaralha o ritmo, os percursos, as etapas, as sucessões e os modelos instituídos para a infância. Afinal de contas, assim também se retiraria do adultocentrismo os mecanismos de idealização e de controle da infância (CHOMBART DE LAUWE, 1991). Ou não são os adultos que, para além de defender as crianças contra os perigos que elas podem suscitar para elas mesmas, esse ser novo em um mundo estranho para si mesma (ARENDT, 2007), também os responsáveis por produzir os controles estriados para seus trajetos? São como incontáveis alfândegas demandando esperas, autorizações, passagens, documentos, justificativas e explicitação de trânsito.

De outro lado, porém, está a viagem da infância em seus próprios alisamentos. E não seria a partir disso que emergiria um sintoma mutacional para os próprios condicionantes do Estado? Em outros termos, não é por intermédio da infância lisa que outras políticas de territórios existenciais poderiam emergir, transfundindo outras experiências relacionais com os afetos e as percepções, tanto singulares quanto potencializadoras de turbilhonares simbólicos, sobretudo em um tempo de empobrecimento e de padronização subjetiva (CARVALHO, 2019)? Portanto, por que não potencializá-las? E não seria a arte campo privilegiado para tanto? 
Guattari (1992), ao anunciar que a arte engendra subjetividades mutantes, fornece indícios de correlação de como a arte é campo, no sentido de espaço, privilegiado para a infância lisa. Se na perspectiva dos componentes educativos, notadamente os disciplinares, a infância é capturada por estriamentos, conceber possibilidades para que experiências educativas coincidam com a infância lisa nos convoca a engendrar trajetos de turbilhão de passagens incessantes. A nosso ver, a arte figura-se aí de maneira privilegiada.

Assumir que a arte engendra subjetividades não dominantes requer concebê-la como território de manifestação expressivo-singular, ou seja, como lugar de passagens cuja topologia é uma pertença livre, em oposição ao excesso de orientação presentes na arte estriada. A arte como trajeto de turbilhão de passagens insinua-se por intermédio de matéria eletiva ou opcional (matière à option), nos termos de Guattari (2011a). É preciso não confundir referida acepção com a dimensão curricular de uma matéria eletiva ou opcional, que se cumpre ou não. Não se trata disso. Pensar a arte como matéria eletiva é conceber todas as possibilidades de conteúdos e de expressão que podem alcançar corpo, forma, contorno, caminho, trajeto, singularidade, efetivação, consistência, enfim, tudo o que é próprio do turbilhão. A arte na perspectiva da política lisa é contraestriante, logo, nada afeita ao que precisa significar, justamente porque tudo é opcional, experimental e eletivo. A matéria eletiva-opcional na arte retira da rotina ordinária das emissões estéticas a obrigatoriedade de elementos do âmbito das justificativas: como fazer? Por que fazer? O que isto representa? Para que fazer? A arte não obriga a nada, exceto ao encontro com outros possíveis, desde que cada possível seja a possibilidade como a afirmação do improvável. De forma muito precisa, diz-nos Blanchot (2010, p. 85): "a possibilidade estabelece a realidade fundando-a: é somente com o poder de sê-lo que se é aquilo que se é".

A arte sendo essa matéria eletiva-opcional permite qualquer possibilidade de expressão porque, ao fundar a sua própria realidade, abre espaço para "as marcas discordantes da existência humana" (BLANCHOT, 2007, p. 30). O possível da arte, assim, é toda afirmação de impossibilidade que a arte estriada renega. E a impossibilidade, arremata Blanchot (2010, p. 91, grifos originais), "não é nada mais do que a característica daquilo a que chamamos tão facilmente experiência, porque, somente há experiência em sentido estrito, onde algo de radicalmente outro está em jogo".

Eis a convergência que nos interessa. A infância lisa, do ponto de vista da arte igualmente lisa, é sempre a radical alteridade para si mesma. A infância lisa é por onde a criança recepciona todo circuito contramodelar de sua própria infância. A arte, então, está para os "trajetos do vagar", na expressão de Deligny (2018a, p. 20), quando se difere e 
se opõe aos trajetos reiterados. O excesso de controle dispensado à arte do Estado, pela educação, está no sentido de exercer constante controle nas experiências simbólicas que podem solapar os circuitos do estriamento. Exercer feixes de poder sobre a variação de direções para cristalizá-las, incidir sobre a criatividade da criança a supervisão que a tudo ritmiza, retirar da matéria eletiva-opcional-artística a sua oportunidade de experimentarse como matéria variável condizem com os trajetos reiterados do estriamento, onde "o lugar está tomado, ocupado desde sempre, fortificado, batizado" (DELIGNY, 2018a, p. 60).

Entretanto, à medida que a arte pode experimentar trajetos do vagar, justamente pela condição de ser ela uma matéria eletiva-opcional, no lugar de uma política de modelagem subjetiva de dominação, o que temos é a arte como descodificação modelar. Dissolvem-se, assim, as linhas estriadas para ceder lugar às composições de movimento absoluto, isto é, pertinentes aos trajetos lisos. A arte encontra na infância lisa a vetorização para seus ensaios. Portanto,

[o] que singulariza tal ou tal traço de uma matéria de expressão é seu caráter de excesso com relação às redundâncias significativas, é o fato que uma diferença jamais pode ser completamente recuperada em uma 'grade de correspondência' (GUATTARI, 2011a, p. 301 , grifos originais).

Mas a educação padece de uma cacofonia que pouco sabe lidar com os excessos. Oportunizar espaços para que as crianças possam viver a arte no fluxo de matérias eletivaopcionais que elas vão experimentando é o caminho inicial para se sair das redundâncias significativas que a tudo estatizam, ou melhor, estriam. Sem se descodificar as condições pelas quais as crianças podem se constituir nos trajetos lisos da infância e da arte, há poucas chances de suas consistências subjetivas serem liberadas das sobrecodificações modelares. A arte que descodifica os códigos dos poderes estriares também catalisa conexões existenciais impensadas, uma vez que percepções, afetos, sensações e relações com matérias eletivo-opcionais não cogitadas manifestam-se de maneira pluridimensional como matéria de valência múltipla de expressões, que passam a ser relativas às intensidades das experimentações, as mais diversas possíveis.

Ao indagarmos: que espaço-lugar se pode traçar para o corpo da criança dançar livremente? Que material pode servir de mero suporte para acolher tintas, cores, texturas e formas sem programação? Quais tecnologias as crianças podem explorar sem receio algum, pois se trata apenas de explorar, para não caírem nas mesmas valas comuns das imagens corporativas-mercadológicas? Quais vozes as crianças podem solfejar fora das tessituras traçadas pelo pedagogismo infantilizador do 'é hora da musiquinha'? Quais estéticas podem emergir como rupturas ao círculo de estriamento da arte do Estado? Pois 
bem, tais questões apontam para as tensões presentes e inescapáveis à peculiar inventividade da arte da infância lisa. Seja como for, a seguinte perspectiva advinda do pensamento de Guattari (1992, p. 115) se delineia:

De um modo mais geral, todo descentramento estético dos pontos de vista, toda multiplicação polifônica dos componentes de expressão, passam pelo pré-requisito de uma desconstrução das estruturas e dos códigos em vigor e por um banho caósmico nas matérias de sensação, a partir das quais torna-se-á possível uma recomposição, uma recriação, um enriquecimento do mundo (um pouco como se fala de urânio enriquecido), uma proliferação não apenas das formas, mas das modalidades de ser.

Algumas ponderações dão pistas da relevância política que a arte, articuladora de descentramento estético, enseja na atualidade. Inegavelmente, a arte aporta componentes experimentais responsáveis por desalienar a criança, ou melhor, de retirá-la dos condicionantes de uma infância estriada. Em primeiro lugar, porque a arte permite à criança uma experimentação autêntica, original e de pertença singular com a matéria eletiva-opcional que ela deseja investir. Em segundo lugar, porque a arte funcionaria como experiência de contramodelização infantil, no sentido que não se está demandando ajustes subjetivos a nenhum circuito programado. O que está em causa condiz com o diagnóstico de Schérer (2009, p. 31, grifos originais):

Criar, para a infância, um espaço artificial, distante do mundo adulto e deliberado por ele, onde a criança é convidada a desempenhar seu papel de criança e nada mais. Ora, a criança é um ser utópico precisamente pelo fato de estar confinada nesse lugar escolhido para ela e que é um vazio, um não-lugar.

Tal horizonte se dispõe no sentido das lutas contra o empobrecimento subjetivo aos quais as crianças são destinadas, notadamente sob o impacto semiótico dos manejos de mercado que a tudo tende a igualar, a fechar em circuitos programados de consumo, a fetichizar conforme o valor da mercadoria e a redundar em sensibilidade programada. As crianças são lançadas, desde cedo, a uma iniciação de semióticas dominantes integrais e que, a todo o momento, atuam como agentes a confiscar suas expressividades singulares, canalizando-as e explorando-as. Carr (2011), Twenge e Campbell (2013) e O'Neil (2020) traduzem em preocupações concretas a rede de superficialidade das sensações programadas; o isolamento narcísico retroalimentado pelo viés da autoimagem ritualizada pela aceitação das aparências impostas; o ajuntamento de padrões por baldes comportamentais, ou seja, por processos de identificação insuflados pelos ajustes comerciais que vêm desenhando para a infância contornos cada vez mais indoor. 
Quando Guattari (1985, p. 50) indagou: "como evitar que as crianças se prendam às semióticas dominantes ao ponto de perder muito cedo toda e qualquer verdadeira liberdade de expressão?", ele estava fornecendo condições para se pensar a interposição das constantes estratégias mutatis mutandis responsáveis por estriar a infância. Afinal de contas, quanto mais precoce se modelizar a subjetividade da criança, mais funcional ao sistema ela será. Por isso mesmo, a arte não interessa como realização experimental da liberdade de expressão, pois aqui se reivindicariam singularidades e diferenças.

Por intermédio da arte, a infância lisa se torna um problema para o Estado. Se a arte aqui é uma luta pela polivocidade de toda e qualquer expressão manifesta em conteúdos eletivo-opcionais, singulares, turbilhonares e contramodelares, logo se vê que a infância estaria longe de se reduzir aos esquemas de equivalência exigidos pelas funções sociais programadas. O campo da liberdade da expressão, assim, sempre foi um perigo para os poderes estáveis do Estado, porque a explosão da padronização alucina a radicalidade das regras, os padrões hegemônicos e os circuitos programados da subjetividade.

A partir dessas considerações, a arte emerge contra aquilo que Benjamin (2004, p. 84) vaticinou: "a banalização de uma existência insuportável". Ele pressentia na explosão comercial dos jogos infantis a hegemonia comercial de valores com suas implicações de captura voltadas para a infância lisa. Mas a arte também é um antídoto contra o que Huizinga (2019, p. 267) denominou de "abastardamento universal da cultura". Em ambas as pontas, sintetizam-se a tomada de ação da infância lisa, esta que cria trajetos outros, e a afirmação de componentes de passagens que não prescindem das matérias de expressão que as crianças podem produzir.

Para além das respostas esquemáticas que a arte do Estado incita, visando aos códigos negociáveis das competências e das adaptações constantes, a infância lisa considera a arte como trajeto de turbilhão de passagens para romper com as cadeias e com os circuitos estriados do utilitarismo, do funcionalismo, das redundâncias dominantes, das matrizes simbólicas e dos trajetos reiterados na educação. Aqui, a infância com a arte diagrama para resistir a todo modelo e a toda modelagem. Diagramatizar é recuar o estriamento. "A linha de fuga faz parte do diagramatismo", asseverou Guattari (2012, p. 529), justamente no sentido de assinalar que o gradiente mais radial do trajeto de alisamento é não se deixar capturar. Os circuitos fechados com suas codificações e sobrecodificações se desorientam no diagramatismo. Coextensivo à matière à option, o diagramatismo antecipa-se às expectativas de controle pelo fato de estar aberto à singularidade expressiva da própria criança. 
Para responder à indagação interposta por Guattari (2011a, p. 189), "em que a aprendizagem, a escola, a partir de uma escritura advinda de toda utilização vibrante esteriliza as ulteriores possibilidades de um diagramatismo criativo?", poderíamos, no mesmo tom autoral, dizer:

O diagramatismo coloca em jogo os agenciamentos transsemióticos mais ou menos desterritorializados, regimes de signos, de encodificação, de catálise etc. que permitem, segundo modalidades particulares, atravessar estratificações de toda natureza (GUATTARI, 2012, p. 510).

O fato de que precisamos considerar a arte uma das possíveis modalidades particulares de se atravessar as estratificações subjetivas, uma vez que elas equivalem aos trajetos estriados, já o sabemos. Mas não soubemos disso quando pressentíamos na infância estriada, com suas demandas de subjetividade de dominação, aquela angústia a prenunciar que o lugar marcado do adulto não precisa coincidir com o lugar da manutenção da idealização de uma infância estriada? E aqui já não seriam lisos demais os termos, a seguir, que poderiam também nos transformar em turbilhão de infância? "Deixar o outro fazer é primeiramente querê-lo outro e deixar querer esse outro querido por obediência à ordem simbólica" (DELIGNY, 2018a, p. 105). E onde nós? Eis algumas pistas deixadas por Guattari (1992, p. 107): "eternidade de um mundo profundamente infantil, que é preciso opor à hiperlucidez da criança em meditação solitária sobre o cosmos ou ao devir criança da poesia, da música, da experiência mística" - questões de arte e de infâncias lisas.

\section{Trajetos que não acabam para as infâncias lisas e a arte}

Sentir tudo de todas as maneiras; saber pensar com as emoções e sentir com o pensamento; não desejar muito senão com a imaginação (PESSOA, 2016, p. 151).

Da afirmação de Guattari (1989, p. 116, grifos originais), "ante toda categorização em termos de objetividade e de subjetividade, um ponto de vista é um ato, uma interação", poderíamos extrair: face à categorização das forças de modelagem subjetiva, a arte é uma interação para se suscitar outros pontos de vistas para a vida, sem categorização, porém.

Há ampla micropolítica de trajetos nos pontos de vista que não são mais do que modos de perspectivar e de valorar a existência. Como se viu, a política de estriamento consolida para a infância situações e contextos que não abrem mão da modelagem subjetiva de dominação. Nesse caso, tudo que se oficializa para a educação tende ao estriamento. O Estado é a nominação sintética por onde a multiplicidade de trajetos estriares convergem, são organizados e aplicados com o intuito de replicar as mesmas 
coordenadas de referência para a produção dos territórios existenciais. A criança é privilegiada em toda essa conjuntura, porque a plasticidade de sua potência precisa ser preparada o quanto antes, conforme os componentes da modelização estriada. Introduzir e manter a criança nos circuitos de hierarquia; deixá-la cativa das etapas programadas de uma infância pressuposta pelos currais e pelas utopias educativas; controlar os fluxos expressivos de cada criança, enfim, tudo isso compõe a complexa trama da infância estriada na criança.

A persistente política de produção de infância estriada aporta as suas consequências imediatas e em longo prazo. De modo imediato, cada criança padece com a lógica dos decalques da infância programada. Nesse contexto, a função da experiência com a arte é conter o trasbordamento da experimentação expressiva da criança. Em todas as direções e possibilidades, a temporalidade programada pesará sobre ela como inserção imediata nos circuitos controlados. A arte, assim, serve como introdução imediata ao ponto de vista do estriamento do Estado. Ao longo prazo, porém, o que se mobiliza é a projeção do adulto estriado sobre a criança capturada. Se é correto dizer que "é a modelização de suas semióticas através da escola que a conduz a uma espécie de processo de indiferenciação (GUATTARI; ROLNIK, 2005, p. 262), não se demora a perceber que a estratégia persistente do estriamento é programar a infância para a adultez indiferenciada. Por sua vez, esta é aquela presa nos mesmos circuitos expressivos, afetivos e perceptivos, todos eles imutáveis, redundantes e banais.

Tudo isso é extremamente funcional aos modos pelo quais as políticas recentes para a educação, a exemplo da BNCC (BRASIL, 2018), retroalimentam a perspectiva de uma educação conforme aos modelos impostos pelo mercado econômico. É gritante a ênfase na adaptação constante, suscitada por competências que precisam ser formatadas como atitude imediata ao que se exige por conformidade. Em momento algum, a arte é concebida como atitude de corte expressivo, experimentação afirmativa do desejo singular, esboço criativo contra-adaptativo ao sistema social ou inventividade cujo valor ultrapassa o demandado pelo mercado de trabalho. Ao contrário, a arte se reduz a um capital simbólico de adaptação. Assim, a infância já está reduzida a um mini-Estado; suas conexões estão dadas como um mapa programado por um GPS, cujas etapas são projetadas sob controle e em ambiente de previsibilidade virtual, do início ao fim. Eis aí, nos termos de Deligny (2018b, p. 124), "crianças murchas de antemão", destituídas de infâncias outras, entabuladas pela persistência perversa da política de estriamento da própria infância do Estado. Por conseguinte, e para reforçar o próprio estriamento, 
O mundo dos adultos atravessa incessantemente as condições da infância negando a meninos e a meninas o direito de romperem com as tragédias muitas vezes cruéis da adultícia (CARVALHO, 2016, p. 81).

Mas não sejamos defensores dissimulados da infância e da criança, que é sua portadora e habitante. Já existem sobrando aos borbotões aqueles e aquelas que

gostam da ordem, dos relatórios escritos para se manterem acobertados e das fofocas para se informar. Ignoram o que uma turma de garotos e garotas pode consumir de energia, de pregos, de tijolos, de solas, de tempo, de ideias, de tudo o mais (DELIGNY, 2018b, p. 17).

Ora, ter concebido a infância lisa por outra política de trajeto exigiu desta análise mostrar que diferentemente dos templates de infância gestados, visando à manutenção de subjetividades de dominação, a criança pode emergir como traço absoluto em trajetos de turbilhão de passagens, pois sempre intenso, topológico e experimental. A proporção do lugar da arte na educação aqui é inversa. No lugar da modelagem e do estriamento, a arte produz lisuras, linhas de escapes das reentrâncias dos poderes que idealizam a arte para a infância e para um estado de arte da infância.

Com a arte e pela arte, educadoras/es podem se tornar criadoras/es de circunstâncias (DELIGNY, 2018b) contra todas as inércias que tendem às linhas estriadas, cujo objetivo precípuo produz automatismo e normalização no funcionamento das abordagens e das experiências com a educação. Emerge, nessas circunstâncias, a concepção de que tanto arte quanto infância não programadas, ou seja, lisas, destinamse à ultrapassagem e ao transbordamento situacional da vida. Aqui, toda matéria eletivaopcional é agenciada, uma vez que ela remarca que à finitude da vida pode ser dada a chance de experimentar outros componentes existenciais, que não apenas os que foram programados para servirem a um circuito fechado de sensação, de percepção, de expressão e de componentes simbólicos e imaginários.

Arte e infância lisa reinventam-se, assim, como resistências aos trajetos de estriamento. E "a resistência significa compreender que os valores nos quais nos deslocamos, o mundo no qual estamos, são marcados por uma finitude radical" (GUATTARI, 2016, p. 121). Soubemos das razões pelas quais a arte é perigosa ao Estado. Contudo, vale insistir na ideia de que ela é fundamental no desenho de outra finitude radical, pois sem outra sensibilidade isso não se alcança. Não é sem razão que o próprio Guattari (2016, p. 121) reconheceu que a resistência neste mundo "é uma resistência das pessoas que reconstroem a sensibilidade através da poesia, da música, pessoas que reconstroem o mundo através de uma relação amorosa, através de outros sistemas 
urbanos, de outros sistemas pedagógicos" (GUATTARI, 2016, p. 121). E não estariam aí também os trajetos da infância lisa? Também não seriam outras sensibilidades infantis às linhas de acesso à vida que têm se estancado por estarem excessivamente fechadas nas políticas de estriamento?

A arte não está dada e nunca estará no âmbito da política de trajetos lisos, tampouco a infância e as experiências de encontros com a educação. Insistir no contrário faz parte do jogo político do estriamento, não se pode esquecer. Uma vez, porém, que as linhas lisas objetivam sair das coordenadas dadas, situação pela qual se criam os espaços de fechamento estriados, o que se ativa é a força de diagramatização. Diagramatizar é alucinar os circuitos de fechamento com aberturas conectivas incessantes, pois o diagrama, para Guattari (2011a; 2011b) se distancia dos modelos. A própria infância deveria ser um diagrama. Na política diagramática, toda e qualquer situação é uma abertura possível para a experimentação e a emersão do turbilhonar. Diagramitizar envolve: "recusar toda ideia de fatalidade, qualquer que seja o nome [...]: divina, histórica, econômica, estrutural, hereditária ou sintagmática" (GUATTARI, 2011b, p. 195). A infância, desse modo, jamais também é uma fatalidade e como tal deve ser recusada.

Ao cabo, quando o texto sustenta que arte é imprescindível como trajeto de turbilhão de passagem para a infância lisa, e vice-versa, é porque a suposição da política diagramática do trajeto liso aí se circunscreve e é considerado. Skliar (2014, p. 178) argumenta que "a tarefa de estar entre crianças consiste em fazer durar a infância todo o tempo que for possível". Não obstante, poderíamos acrescentar: a tarefa de estar entre as crianças consiste ainda em fazer durar a infância em todos os espaços, todas as direções e expressões possíveis.

Estamos longe de deflagrar os turbilhões necessários que, com seus coeficientes mutacionais de experimentação, pudessem abranger amplamente os domínios estriados que atravessam de maneira ampla a infância, e modificá-los. Mas um passo importante e crucial seria dado se a arte, nas experiências educativas, pudesse ser tramada e tecida como matéria eletiva-opcional aberta, experimental, farta e acessível para as crianças não deterem diante de si mesmas em função de uma infância que as estriam. Afinal de contas, a infância que interessa à criança é a do turbilhão.

\section{Referências}

ARENDT, H. Entre o passado e o futuro. São Paulo: Perspectiva, 2007. 
BENJAMIN, W. Reflexões sobre a criança, o brinquedo e a educação. São Paulo: Editora 34, 2004.

BLANCHOT, M. A conversa infinita. A experiência limite. São Paulo: Escuta, 2007.

BLANCHOT, M. A conversa infinita. A palavra plural. São Paulo: Escuta, 2010.

BRASIL. Ministério da Educação. Base Nacional Comum Curricular. Brasília: Ministério da Educação, 2018. Disponível em: <http://basenacionalcomum.mec.gov.br/ images/BNCC_EI_EF_110518_versaofinal_site.pdf>. Acesso em: 20 abr. 2021.

BURROUGHS, W. S. Almoço nu. São Paulo: Companhia das Letras, 2016.

CARR, N. The Shallows. What the internet is doing to our brains. New York: Norton, 2011.

CARVALHO, A. F. de. Foucault e as infâncias incendiárias: experiências de outras verdades e de outras heterotopias. Childhood \& Philosophie, Rio de Janeiro, v. 12, n. 23, p. 6586, jan./abr. 2016.

CARVALHO, A. F. de. A emersão do homo friabilis: subjetivação em tempo de cleptoafetividade. Educação e Filosofia, Uberlância, v. 33, n. 68, p. 591-614, mai./ago. 2019.

CARVALHO, A. F. de. Foucault e o neoliberalismo de subjetividades precárias: incidências na escola pública brasileira. Revista Interinstitucional Artes de Educar, Rio de Janeiro, v. 6, n. 3, p. 935-956, set./dez. 2020.

CARVALHO, A. F. de; GALLO, S. Do sedentarismo ao nomadismo: intervenções para pensar e agir de outros modos na educação. Educ. Tem. Dig., Campinas, v. 12, n. 1, p. 280-302, jul./dez. 2010

CHOMBART DE LAUWE, M-J. Um outro mundo: a infância. São Paulo: Perspectiva/EDUSP, 1991.

DELEUZE, G.; GUATTARI, F. Mil Platôs. v. 5. São Paulo: Editora 34, 2012.

DELIGNY, F. O aracniano e outros textos. São Paulo: N-1, 2018a.

DELIGNY, F. Os vagabundos eficazes. Operários, artistas, revolucionários: educadores. São Paulo: N-1, 2018 b.

FREINET, C. Le maître insurgé. Paris: Éditions Libertalia, 2016.

GUATTARI, F. Revolução Molecular: pulsações políticas do desejo. São Paulo: Brasiliense, 1985.

GUATTARI, F. Cartographies schizoanalytiques. Paris: Galilée, 1989.

GUATTARI, F. Caosmose. Um novo paradigma estético. São Paulo: Editora 34, 1992.

GUATTARI, F. Les années d'hiver. Paris: Les Prairies Ordinaires, 2009.

GUATTARI, F. Lignes de fuites. Pour un autre monde de possibles. Paris: L'Aube, 2011a.

Revista Digital do LAV - Santa Maria - vol. 14, n. 2, p. 07 - 29 - mai./ago. 2021 ISSN 1983 - 7348 
GUATTARI, F. L'inconscient machinique. Essais de schizo-analyse. Paris: Éditions Recherches, 2011b.

GUATTARI, F. La révolution moleculaire. Paris: Les Prairies Ordinaires, 2012.

GUATTARI, F. Qu'est-ce que l'écosophie? IMEC: IMEC/Lignes, 2013.

GUATTARI, F. Confrontações. Conversas com Kuniichi Uno e Laymert Garcia dos Santos. São Paulo, N-1, 2016.

GUATTARI, F.; ROLNIK, S. Micropolíticas. Cartografias do desejo. Petrópolis: Vozes, 2005.

HUIZINGA, J. O outono da Idade Média. São Paulo: CosacNaify, 2016.

HUIZINGA, J. Homo Ludens. São Paulo: Perspectiva, 2019.

MILLER, H. Sexus. São Paulo: Companhia das Letras, 2004.

MONTES, G. El corral de la infancia. México: Fondo de Cultura Económica, 2002.

OECD. Preparing our youth for an inclusive and sustainable world. The OECD PISA global competence framework. Organization for Economic Co-operation and development - OECD: 2018. Disponível em: <https://www.oecd.org/pisa/Handbook-PISA-2018-GlobalCompetence.pdf> Acesso em: 20 abr. 2021.

O'NEIL, C. Algoritmos de destruição em massa. Como o big data aumenta a desigualdade e ameaça a democracia. São Paulo: Rua do Sabão, 2020.

PESSOA, F. Livro do desassossego. São Paulo: Companhia das Letras, 2016.

SCHÉRER, R. Infantis. Charles Fourier e a infância para além das crianças. Belo Horizonte: Autêntica, 2009.

SKLIAR, C. Desobeder a linguagem. Educar. Belo Horizonte, 2014.

STEINBERG, S. R.; KINCHELOE, J. L. Cultura infantil. A construção corporativa da infância. Rio de Janeiro: Civilização Brasileira, 2001.

STERN, D. N. O momento presente na psicoterapia e na vida cotidiana. Rio de Janeiro: Record, 2007.

SZYMBORSKA, W. Um amor feliz. São Paulo: Companhia das Letras, 2016.

TWENGE, J. M.; CAMPBELL, W. K. The narcissism epidemic. Living in the age of entitlement. New York: Atria Paperback, 2013.

WINNICOTT, D. W. A criança e o seu mundo. Rio de Janeiro: GEN/LTC, 2019.

ZAMIÁTIN, I. Nós. São Paulo: Editora 34, 2017.

' Doutor em Filosofia pela Universidade de São Paulo (USP); doutor em Educação pela Universidade Estadual de Campinas (UNICAMP), na área de Psicologia da Educação; mestre 
em Educação também pela UNICAMP, na área de Educação, Sociedade e Cultura; ainda possui especialização em Psicoterapia Familiar e de Casal pelo Centro de Formação e Assistência à Saúde (CEFAS/Campinas). Pesquisador permanente do Programa de PósGraduação em Educação da UNIFESP, na linha de Educação: Desigualdade, Diferença e Inclusão, investigando diferenças, singularidades e processos de subjetividades na sociedade contemporânea, a partir de referenciais da filosofia contemporânea e da psicanálise. Atualmente é Professor Associado 3 no Departamento de Educação da Universidade Federal de Lavras (UFLA). Assessor científico da FAPESP e do CNPq (PIBIC/AF/PIBITI). Pesquisador PQ 2 - CNPq.

Como citar esse artigo:

CARVALHO, Alexandre Filordi. Das infâncias estriadas às infâncias lisas: experimentar trajetos de arte na educação. Revista Digital do LAV, Santa Maria: UFSM, v. 14, n. 2, p. 07-29, mai./ago. 2021. 